JOPAT Vol 19(2), 448 - 465 July - Dec. 2020 Edition.

ISSN2636 - 5448. Https://dx.doi.org/10.4314/jopat.v19i2.2

\title{
PREPARATION AND EVALUATION OF THE PHYSICOCHEMICAL AND STABILITY PROPERTIES OF THREE HERBAL TEA BLENDS DERIVED FROM FOUR NATIVE HERBS
}

\author{
${ }^{1,2}$ Philip F. Builders, ${ }^{1}$ Boma B. Mohammed, ${ }^{1}$ Yahaya Z. Sule \\ ${ }^{1}$ Department of Pharmaceutics and Industrial Pharmacy Kaduna State University \\ ${ }^{2}$ Department of Pharmaceutical Technology and Raw Material Development, \\ National Institute for Pharmaceutical Research and Development, Abuja Nigeria
}

\begin{abstract}
Herbal teas consist of mono and sometimes poly-herbal recipes of herbs with acclaimed health benefits which are often brewed as infusion or decoction. Three variants of poly-herbal teas containing Herbiscus sabdariffa, Moringa oleifera, Citrus limon, and Zingiber officinale were prepared and evaluated for their physicochemical and stability properties. Intrinsic physicochemical properties that include organoleptic, ash value, $\mathrm{pH}$ of brew solutions, extractive matter as well as non-intrinsic properties such as moisture content, flow and particle size of granules and dust leak from teabags were determined. Also, the effects of stressful storage conditions on some physicochemical properties were evaluated. The different tea blends showed remarkable differences in their physicochemical properties. The products also showed discrepancies in stability parameters such as appearance, $\mathrm{pH}$ of the brew and antioxidant properties when stored under different conditions. In all, the herbal tea showed good physicochemical and stability properties that are characteristic of a good finished herbal product.
\end{abstract}

Keywords: Poly-herbal tea, herbal tea bags, physicochemical properties, stability

E-mail Address: philsonsky@yahoo.com

\section{INTRODUCTION}

The use of herbal medicine is an age-long system of healthcare which is deeply enshrined in the culture of Africans and many other peoples of the world. In time past people have relied on herbs as the primary healthcare system with much success. Despite modernization and the proliferation of the conventional healthcare system some people still show personal preferences for herbal medicine. Formulating herbal recipes into tea bags will afford a convenient and safe use of these herbs.

In recent times there has been an apparent upsurge in the popularity and use of herbal teas $(1,2)$. This corresponds with the contemporary global increase in the popularity and use of herbal medicines (3). Herbal teas therefore belong to a rapidly expanding market of wellness beverages $(4,5)$. 
The classical tea is an infusion derived from the leaves and/or other aerial parts of Camellia sinesis. Herbal teas are generally infusions or decoctions of mono- or poly-herbal recipes brewed from herbal materials and are often used for their acclaimed health benefits as compared to the aroma, flavor and caffeine stimulant boost of the brew of $C$. sinesis $(6,7)$. The herbal materials may consist of one or more botanical parts such as leaves, fruits, stems, roots, barks etc. Although they are referred to as tea they are nevertheless technically not the classical tea but herbal materials (8). These herbal medicines are only officially allowed to be called tea only if the name of the plant is included before the word tea to distinguish them from the classical tea obtained from $C$. sinesis. Herbal teas often do not contain caffeine (9). They are often used for their therapeutic and/or nutritional benefits, depending on their indication or folk medicinal claims $(10,11)$.

In Nigeria, there are numerous herbs with acclaimed nutritive and medicinal benefits that are prepared as infusions and decoctions for traditional home use. Among such herbs are $M$. oleifera, $H$. sabdariffa, Z. officianale and $C$. limon. These herbs are well known in Nigerian and constitute household condiments in several folk delicacies and beverages (12). Brews derived from their decoctions and infusions are widely consumed as herbal teas for their nutritive and medicinal benefits. This thus serves as the impetus to prepare and characterize polyherbal tea blends derived from known folk recipes containing these herbs. The physicochemical properties and any changes which may occur in storage especially under stressful environmental conditions are expected to affect their stability and safety. The aim of this study, therefore, is to prepare and evaluate the physicochemical and stability properties of the different blends of poly-herbal teas derived from the folk recipe containing $M$. oleifera, $H$. sabdariffa, Z. officianale and C. limon by using simple conventional techniques.

\section{MATERIALS AND METHOD}

\section{MATERIALS}

Buffer tablets 4, 7 and 9 and silica gel, were obtained from Sigma-Aldrich, Germany. Empty tea bags were purchased from Jumia online trading company. Hibiscus sabdariffa dry calyces, Zingiber officinale rhyzome, and Citrus limon fruits were bought from the Kaduna central market. Moringer oleefera leaves were collected from a farm in Abaji, Abuja.

\section{METHODS}

\section{Collection and Processing of Herbs}

Z. officinale: The fresh rhizomes were bought from the open market in Kaduna. The rhizome was scrapped to remove sand clumps, rotten and fibrous sections. The ginger was washed several times with a copious amount of potable water. This was then cut into small sizes of about $2 \mathrm{~mm}$ Journal of Phytomedicine and Therapeutics 2020; Vol 19(2): 448 
length with a kitchen knife $(13,14)$. The cut pieces of rhizome were then pulverized with a kitchen blender (Kenwood, Japan). The wet mass of the rhizome pulp was dried and screened through a sieve of $1 \mathrm{~mm}$ mesh size. The dry powder was then packed in a waterproof bag and stored in a cool dark place until used.

M. oleifera: The fresh leaves of M. oleifera were then pulverized while still wet with a kitchen blender (Kenwood, Japan). The wet mass of the calyces was then dried and then screened through a sieve of $1 \mathrm{~mm}$ mesh size. The powder was then packed in a waterproof bag and stored in a cool dark place until used.

C. limon: The fruits of C. limon was bought in Kaduna Central Market. The fruits were washed with copious quantities of water. Then the juice was extracted using a manual hand extractor and used as freshly prepared.

\section{Formulation of herbal tea}

Quantities of appropriately processed herbs ( $H$. sabdariffa, $M$. oleifera, and $Z$. officinale) required to produce 50 tea bags were weighed out into a large porcelain mortar such that each tea bag contains $5 \mathrm{~g}$ of the mixture of herbal materials and $3 \mathrm{~mL}$ of the binder solution $(2 \%$ $\mathrm{w} / \mathrm{v}$ Acacia solution) as presented in Table 1. The mixture was massed in the mortar and passed through the sieve. The wet granules were transferred to a hot air oven set at $50{ }^{\circ} \mathrm{C}$ and allowed to stay for 10 minutes. The granules were again passed through the same sieve and dried again for 20 minutes. The dry granules were then packed in a polythene bag, stored in a cool dry place until used for further analysis, and some dispensed into the tea bags and appropriately sealed.

\section{Physicochemical evaluation}

\section{Organoleptic properties}

The color, odor and taste of the tea brews were evaluated: A 5 g quantity of the dry herbal tea products was placed in a Petri dish. A panel of six assessors was co-opted to evaluate the colour, smell, taste and texture of the tea granules (15).

\section{Ash value}

The International Organization for Standardization (ISO) 1575:1987 methods for determination of total ash in tea reviewed and confirmed in 2015 was used (16). Five teabags were randomly selected from each formulation and the content emptied into a large Petri dish. A $2 \mathrm{~g}$ quantity of the herbal material was weighed out into a crucible which has initially been heated to $105 \pm 2^{\circ} \mathrm{C}$ for $5 \mathrm{~min}$ and placed in a desiccator until use. The crucible containing the herbal material was then incinerated. The heating temperature was $525 \pm 25{ }^{\circ} \mathrm{C}$. The crucible was allowed to cool before the weight was determined. Then it was again heated for 30 min and reweighed. This was repeated twice until a constant weight was obtained. The percentage of ash value was determined using Equation 1. 
$\%$ ash value $=\frac{W_{3}-W_{1}}{W 2-W 1} \times 100 \quad \ldots .1$

where $\mathrm{W}_{1}=$ weight of ash and crucible; $\mathrm{W}_{2}=$ weight of granule and crucible; $\mathrm{W}_{3}=$ weight of crucible.

\section{Moisture content}

The World Health Organizational method indicated for quality control of medicinal plant materials was adopted (17). Five teabags were randomly selected from each formulation and the content emptied into a large Petri dish. A $3 \mathrm{~g}$ quantity of the herbal material was weighed out into an evaporating dish crucible which has initially been heated to $105 \pm 2{ }^{\circ} \mathrm{C}$ for $5 \mathrm{~min}$ and placed in a desiccator until use.

The evaporating dish containing the granules put in an oven maintained at $105 \pm 2{ }^{\circ} \mathrm{C}$, the crucible was removed every $30 \mathrm{~min}$ and weighed until no change in weight was obtained over two consecutive readings. This was repeated three times. The percentage of moisture content was determined using Equation 2.

$\%$ moisture content $=\frac{C 2-C 3 X 100}{C 2-C 1} \quad \ldots \ldots 2$

where: $\mathrm{C} 1$ =weight of the empty evaporating dish

$$
\mathrm{C} 2 \text { = weight } \text { of crucible }+ \text { sample before }
$$

heating

C3 = weight of crucible $=$ sample after heating.

\section{Extractive matter}

A tea bag corresponding to $5 \mathrm{~g}$ of the herbal tea
$250 \mathrm{~mL}$ of hot boiling potable water $\left(\approx 100^{\circ} \mathrm{C}\right)$ in a $250 \mathrm{~mL}$ beaker flask. The water containing the tea bag was allowed to stand for $24 \mathrm{~h}$ with intermittent stirring. A $20 \mathrm{~mL}$ quantity of the brew was transferred into a pre-weighed porcelain dish and the water evaporated on a water bath set at $100 \pm 2{ }^{\circ} \mathrm{C}$. The porcelain dish was then transferred into a hot air oven set at 50 $\pm 2{ }^{\circ} \mathrm{C}$ and allowed to stay for $1 \mathrm{~h}$. The percentage of the soluble extractive matter was calculated with reference to the dry weight of the sample without the empty bag (18).

\section{pH of brew}

A tea bag corresponding to $5 \mathrm{~g}$ of the herbal blend was brewed using $250 \mathrm{~mL}$ of hot boiling water $\left(\approx 100{ }^{\circ} \mathrm{C}\right)$ in a $250 \mathrm{~mL}$ conical flask. The brew was allowed to cool to $27 \pm 2{ }^{\circ} \mathrm{C}$. The $\mathrm{pH}$ of the brew solution was determined using a digital pH meter (SPER Scientific, China) (19). The brew was stored in a refrigerator at $\approx 5{ }^{\circ} \mathrm{C}$ and the $\mathrm{pH}$ determined weekly for a four week period.

\section{Dust leak}

Two tea bags of the products were selected at random, weighed and placed in a friability tester. The machine was operated for 4 min to undergo the abrasive fall. After the expiration of the 4 min, the tea bags were dusted and weighed.

The percentage leak was evaluated using the formula:

$$
\frac{W 1-W 2}{W 1} X 100 \quad \ldots .3
$$


where: $\mathrm{W}_{1}$ is the initial weight before the leak test $\mathrm{W}_{2}$ is the weight after the test.

\section{Particle size analysis of herbal tea granules}

A $50 \mathrm{~g}$ quantity of the granules of each formulation was transferred to a set of sieves mounted on a sieve shaker (Jin-Ling Shang, China). The sieves were arranged in descendingorder: $0.9 \mathrm{~mm}, 0.45 \mathrm{~mm}, 0.28 \mathrm{~mm}$, $0.18 \mathrm{~mm}, 0.15 \mathrm{~mm}$ and pan collector. The vibration was set for $10 \mathrm{~min}$. After the vibration, the granules retained in each sieve and the collecting pan were weighed and recorded. This evaluation was done three times. The data was collected and recorded as particle oversize (20).

\section{Flow properties of granules}

The angle of repose: The static angle of repose (a) was measured according to the fixed funnel and free-standing cone method (20). A $50 \mathrm{~g}$ quantity of powder was transferred into a funnel of $1 \mathrm{~cm}$ orifice. The funnel was clamped $10 \mathrm{~cm}$ from the base (such that the funnel neck tip was $10 \mathrm{~cm}$ from the flat surface). The tip of the funnel neck was closed with a finger until all the granules have been transferred. The granules were then allowed to flow through to the surface. When all the granules had completely drained, the height and the diameter of the granule mound on the surface was measured and recorded. This was repeated three times.

The angle of repose was then calculated using the formula:
$\operatorname{Tan} \Theta^{\circ}=2 \mathrm{H} / \mathrm{D}$

$\ldots 4$

where: $\Theta^{\circ}=$ angle of repose, $\mathrm{H}=$ height and $\mathrm{D}=$ diameter.

Bulk and tapped densities: The volume occupied by $50 \mathrm{~g}$ of each of the granules was determined using a $200 \mathrm{~mL}$ graduated measuring cylinder. The tapped volume which corresponds to the final volume of consolidation after tapping with an automated tapping machine (Stampfvolumeter, STAV 2003JEF, Germany) was determined. The bulk $\left(\mathrm{V}_{\mathrm{o}}\right)$ and tapped $\left(\mathrm{V}_{\mathrm{T}}\right)$ volumes were evaluated (20).

The bulk and tapped densities were calculated as the ratio of weight to volume $\left(V_{0}\right.$ and $V_{T}$, respectively) as presented by Equation 5:

Mass $(\mathrm{g}) /$ Volume $\left(\mathrm{V}_{\mathrm{o}}\right.$ or $\left.\mathrm{V}_{\mathrm{T}}\right) \quad \ldots .5$

Compressibility index: The Compressibility index (CI \%) was extrapolated from the bulk and tapped densities using Equation 6:

Compressibilityindex $(\%)=\frac{P T-P_{0}}{P T} X 100 \quad \ldots 66$

\section{Stability studies}

The effect of storage on the $\mathrm{pH}$ of tea brew: storage in the refrigerator at $0^{\circ} \mathrm{C}$

A tea bag corresponding to $5 \mathrm{~g}$ of the herbal blend was brewed using $250 \mathrm{~mL}$ of hot freshly boiled water $\left(\approx 100{ }^{\circ} \mathrm{C}\right)$ in a $250 \mathrm{~mL}$ conical flask. The brew was allowed to cool to room temperature $\left(\approx 27^{\circ} \mathrm{C}\right)$. The $\mathrm{pH}$ of the brew solution was determined using a digital $\mathrm{pH}$ meter (SPER Scientific, China). The brew was 
stored in a refrigerator $\left(\approx 5^{\circ} \mathrm{C}\right)$ and the $\mathrm{pH}$ was determined weekly for four weeks.

\section{The effect of storage of teabags on the pH of tea brews}

Six teabags of each formula were divided into two groups. Each three of the herbal tea variants were selected and stored in the photostability chamber while the other three were stored in a conducive home environment (cool dark home kitchen cupboard) for 12 weeks. At the end of this period, the teas were each brewed using 250 $\mathrm{mL}$ of hot freshly boiled water $\left(\approx 100^{\circ} \mathrm{C}\right)$ in a $250 \mathrm{~mL}$ conical flask. The brew was allowed to cool to $27 \pm 2{ }^{\circ} \mathrm{C}$. The $\mathrm{pH}$ of the brew solution was determined using a digital $\mathrm{pH}$ meter (SPER Scientific, China).

\section{The Effect of storage condition on the DPPH} free radical scavenging effect of herbal tea brew

Three tea bags of each of the sample formulas were selected and stored at ambient temperature in a cool dark place and in a photostability chamber for 12 weeks. At the end of this period, each sample of the teas was emptied into a 250 $\mathrm{mL}$ beaker and mixed, after which a $1 \mathrm{~g}$ quantity was weighed into a sample bottle and $20 \mathrm{~mL}$ of ethanol added. The mixture was allowed to stand with continuous shaking on a shaker for $24 \mathrm{~h}$.

Radical scavenging activity of the ethanol extract of the herbal tea samples against stable 2,
2 diphenyl 2 picryl hydrazyl hydrate (DPPH) was determined by the slightly modified method of Brand-Williams et al. (21). A $0.1 \mathrm{~mL}$ of the stock solution (equivalent to $0.1 \%$ ) was transferred into a screw-capped test tube with a micropipette, $1 \mathrm{~mL}$ quantity of freshly made 1 $\mathrm{mM}$ of DPPH ethanol solution was added and made up to $10 \mathrm{~mL}$ with ethanol. The mixture was shaken and allowed to stand for $30 \mathrm{~min}$ in the dark. The absorbance of the mixture was then determined at $517 \mathrm{~nm}$ using a UV spectrophotometer. This was also done for the same concentration of ascorbic acid.

The experiment was carried out in triplicate. Radical scavenging activity was calculated by the following formula.

$\%$ Inhibition $=\left[\left(\mathrm{A}_{\mathrm{B}}-\mathrm{A}_{\mathrm{A}}\right) / \mathrm{A}_{\mathrm{B}}\right] \times 100 \quad \ldots .7$ where: $A_{B}=$ absorption of blank sample and $\mathrm{A}_{\mathrm{A}}=$ absorption of test extract solution.

\subsubsection{Statistical Analysis}

Results were expressed as the mean \pm standard error of the mean (SEM).

The data was analyzed using one-way analysis of variance (ANOVA).

\section{RESULTS AND DISCUSSION}

Preparation herbs

Preparation of herbs in this context includes washing, drying, milling, sieving, packing and labeling. All these processes are critical to the production of standardized herbal medicine. Attention was given to every aspect of the 
preparation processes because overlooking any may result in a defective product. The washing of the $M$. oleifera leaves immediately after collection affords a thorough cleaning of the leaves and prevents it from falling off the stalk as this is a characteristic of this plant.

The wet milling of the various herbs is part of the technique used to ensure faster leaching of extracts of the infusion. The drying in the oven of the initially air-dried materials ensures that the required moisture content necessary for optimal microbial control and stability is obtained. The drying controls moisture content in the various raw materials and ensures that accurate quantities of herbal materials are obtained always. Packaging the dry material in sealable poly-bags helps prevent moisture uptake from the atmosphere and labeling with indelible ink is to ensure proper identification and prevent mix-ups. The prepared raw materials are stored in a cool dark place to prevent any degradation that may be induced by light and heat. By so doing the herbs were maintained in good condition for use (22).

\section{Formulation of herbal tea}

The objective of formulating the herbs as tea bags is to present the herbs in a form that is stable, easy to use and acceptable to the user. Formulation evaluations showed good throughput and acceptable products. The herbal blends as presented in leachable tea bags are easy to handle and brew, to produce a palatable herbal tea with an acceptable strong aroma and colour. The granules particle sizes were also controlled by the length of time and speed of pulverization as well as sieving. The controlled multi-particulate granules effectively controlled the leaching, followability and acceptable bulkiness.

\section{Organoleptic properties of tea granules}

The organoleptic properties of the herbal teas are presented in Table 2. The organoleptic properties of the various tea blend were determined by evaluating basic intrinsic properties such as colour, smell, taste and texture. Organoleptic evaluation is a low cost and first-line means of identification and assessment of the quality of herbs and herbal materials using the perceptible senses. Though the assessment and judgment may appear to be subjective they are usually the simplest and rather most accurate means of identification and quality assessment (23-25). The colour, smell, feel and taste of the various tea blends reflect the characteristics of the various components that make up the recipe of each polyherbal blend.

\section{Ash value}

Ash value is also called total ash. This is the residue remaining after incineration of the test sample. Ash value helps determine the quality and purity of the powdered herb or herbal material. This parameter is useful in determining the authenticity and purity of the herbal material (25). The ash of most plant materials contains calcium carbonate as its major component, this 
constitutes 25 to $45 \%$ of the ash. Other components include potash $(\approx 10 \%)$, iron, manganese, zinc, copper and heavy metals. The ash values of the herbal teas are presented in Table 3. The differences in the ash value of the various herbal tea blends constitute an intrinsic property of the herbs that make up the tea.

\section{Moisture content}

The moisture content of the herbal teas is presented in Table 3. The moisture content of all the herbal teabags were less than $10 \%$, which is recommended for effective stable storage (26, 27). The measurement of the moisture content especially for herbal materials and products that will be stored for a long time before use is very important. Moisture content is a quality factor in the storage and preservation of herbs and controls the stability of herbal materials especially with regards to various degradation agents such as bacteria and fungi growth as well as enzymatic activities (28). The moisture content of fresh ginger and $M$. oleifera are up to $89 \%$, while that of the commercially available H. sabdariffa is about $26 \%(28,29)$. To ensure stability during storage of these herbal materials, effective drying was carried out to reduce the moisture content to below $10 \%$.

\section{Extractive matter}

The water extractive matter relates especially to compounds that can be solubilized and extracted by water, this includes such compounds as sugar, acids and various inorganic compounds, which may include minerals and salts. The water extractive matter determined for the various herbal teas is presented in Table 3. The variable extractive matter shown by the different herbal teas may be related to the differences in the herbal ingredients that constitute the recipe. Also, the high extractive matter may be related to the high solubility of the biochemical constituent in water. The relative high extractive matter experienced with water may be the reason for the acclaimed health benefits of $H$. sabdariffa, M. oleifera, Z. officinale and $C$. limon.

\section{pH of herbal tea brew}

$\mathrm{pH}$ is an important parameter in food quality and production. Due to the logarithmic nature of the measurement, even small changes in $\mathrm{pH}$ are significant. The difference of one $\mathrm{pH}$ level, such as $\mathrm{pH} 3$ and $\mathrm{pH} 2$ represents a ten-fold increase in acid concentration; a change of just 0.3 represents a doubling of acid concentration. The $\mathrm{pH}$ value of a food is a direct function of the free hydrogen ions present in that food. Most acidic drinks are often characterized by a distinct sour flavor. The $\mathrm{pH}$ of the tea brewed with clean potable water is presented in Table 3 . The $\mathrm{pH}$ varied from 1.6 to 2.04 . The $\mathrm{pH}$ shows the relative differences in the phyto-constituents of the herbal tea. The teas containing $H$. sabdariffa all showed low $\mathrm{pH}$ values, which relates to the intrinsic characteristic $\mathrm{pH}$ of $H$. sabdariffa. $Z$. officinale showed relatively higher $\mathrm{pH}$ that corresponds to alkaline $\mathrm{pH}$ while that of $M$. 
oleifera is slightly acid. The lower relative $\mathrm{pH}$ values may show the overwhelming effect of certain ingredients in the herbal blends. Though the tea brew solution shows low $\mathrm{pH}$ values, it does not cause harm when swallowed, this may be related to the low concentration of hydrogen ions in the solution.

\section{Flow properties herbal tea granules}

Although, the different batch samples of the herbal tea used for both the physicochemical and bio characterization was produced using bench top manual hand fill, automation will however be required during large scale production (30). The mixing and tea bag filling processes are among the most important processes that will require automation. Powder flow is a key requirement for such granule production and packaging. The mixing of the component granules and the filling of the herbal tea granules into the tea bag as well as the sealing will require that the materials and products have a good flow. The effective flow of the granules from the hopper into the tea bags or packaging material is very important and determines the weight uniformity of the filled teabags and the packed tea.

The flow properties as determined by the indirect methods by estimating the Carr's compressibility and angle of repose are presented in Table 3.

The bulk and tapped densities are applied to determine the granule compressibility index as an indirect method for predicting the flow properties of the herbal granules (20). The lower values derived for the bulk and tapped densities for granules (Table 3) are due to the higher bulk volume per unit weight, a property imparted on herbal granules by the individual ingredients of the herbal recipes. Generally, when assessing powder flow with the Carr's compressibility index, values below $15 \%$ represent good flow and $15 \%$ to $25 \%$ represent fair flow, while values above $25 \%$ are indicative of poor flow (20). The flow of powders as assessed by the angle of repose is based on the inter-particulate cohesion: values less than $25^{\circ}$ are indicative of "very-good flow", whereas values equal and greater than $25^{\circ}$ but less than $50^{\circ}$ indicate "good flow" while values greater than $50^{\circ}$ indicate "poor flow". Thus, the results presented in Table 3 , relating to the angle of repose of the herbal tea granules indicates excellent flow since their angle of repose wereall less than $25^{\circ}$.

\section{Particle size of herbal tea granules}

The frequency of different particle sizes of granules of the herbal tea is presented in Fig. 2. The particle size of the herbal tea granules is very important as this affects other important parameters such as handling and mixing during production, leaching time, leakage of tea powder from the teabags, flow properties of granules and variation of weight of the filled teabags. Particles with sizes less than $0.15 \mathrm{~mm}$ are responsible for the fine particles that leak out of the tea bags as fines. Large particles as could be 
likened to those of $1 \mathrm{~mm}$ and above are more

likely to delay the brewing time when infused in water. The results of the particle size analysis corroborate the results obtained for the dust leak from the various herbal teabags. The particle sizes analysis of the different herbal teas shows acceptable content as only a small fraction are in the fine and large coarse particle sizes. The particle size properties of the herbal teas are not intrinsic to the herbal materials but result from the techniques used during processing. Hence the particle size can be modified by changing the methods, equipment and time used for particle size reduction, granulation technique and other related processes.

\section{Leakage of granule fines from tea bags}

This test relates to the ability of the herbal tea bags to withstand handling especially during transportation and other events involving vibration and movements. Leakage occurs when very fine particles migrate out through the pores of the tea bags. The leakage of herbal material from tea bags is presented in Table 3. This relates to the amount of material that escape from the pores of the tea bags and lost. The material that is lost relates to the number of fines contained in tea bag packaging. This loss is not an intrinsic property but is dependent on the formulation technology. The exclusion of fines by processes such as the formation of stable granules larger than the size of fines and/or the physical exclusion of the fines will diminish such leakages. This test may be related to the friability test of tablets. Friability is an official test with a limit of $1 \%$. The low leak values obtained for the various herbal teabags could be attributed to the stable granules and low quantities of fines in the herbal teas' granule formulations.

\section{Stability of herbal tea}

The stability of the physical, chemical and functional properties of a product is important for the continuous maintenance of the efficacy and safety of the product until use (31). The purpose of stability testing is to provide evidence of how the quality of the product will vary with time under the influence of a variety of environmental factors such as temperature, humidity and light. The test is most appropriately carried out in the official container or packaging material. The maintenance of the various physical, chemical and functional properties of a product is important to preserve the efficacy and safety of the product. The properties of the herbal tea, such as physical appearance, the color of the brew, $\mathrm{pH}$ are affected by the environmental stress factors such as light, high humidity and temperature.

\section{Effect of storage organoleptic properties on the tea brew}

The colour of the brew of teas is often characteristic of the herbal material that constitutes the ingredients. The colour also constitutes one of the major attractions to the patronage and consumption of the product. The colour of the three herbal tea blends was similar 
(Table 4) despite the differences in the ingredients contained in the recipe. However, the tilt of the colour of the brew towards red reflects the overwhelming colour of $H$. sabdariffa. The red colour is usually intensified when acidic substances such as the juices of $C$. limon is added to it $(32,33)$. The storage condition of the teabags was shown to affect the colour of the brews. The samples stored at good ambient controlled storage conditions retained the initial colour and appearance of the various teas as compared to those stored under stress conditions.

\section{The effect of storage on the pH of tea brews} of the herbal teas

The $\mathrm{pH}$ of the herbal tea brews is presented in Table 5. The $\mathrm{pH}$ of the poly-herbal teas was determined as one of the intrinsic properties of the products $(34,35)$. The $\mathrm{pH}$ of the various brews showed acidic $\mathrm{pH}$. The differences in the $\mathrm{pH}$ of the three herbal teas may be related to the herbal materials that make up the recipe. The low $\mathrm{pH}$ of the poly-herbal tea blends is characteristic of the chemical components of the herbs.. The $\mathrm{pH}$ of the different herbal tea showed remarkable differences for the batches stored in normal protected storage conditions and those stored under stress conditions in a photostability chamber at $40 \pm 2{ }^{\circ} \mathrm{C}$, thus, indicating probable instability when the teas are stored under stress conditions (36). Whereas, there were no remarkable differences between the $\mathrm{pH}$ of the brews obtained immediately after production and those stored at good ambient controlled conditions.

\section{The effect of storage on the DPPH free} radical scavenging effect of the herbal teas.

One of the benefits of herbal medicine is its antioxidant properties, which are elicited by some of the bio-chemicals they contain $(37,38)$. These biochemicals can mop-up oxidative species that often occur as free radicals. The generation and sustenance of free radicals in the body are responsible for various oxidative stresses that are responsible for several diseases. Oxidative stress reflects an imbalance between the systemic manifestation of reactive oxygen species and the body's ability to readily detoxify these reactive intermediates or to repair the resulting damage they cause $(39,40)$. The antioxidant substances often occur in many beneficial herbs as phenolic compounds such as flavonoids and glycosides. They react directly with reactive oxygen species to prevent them from reaching their biological targets which include various cells that make up important tissues and organs. It has been proposed that one of the major mechanisms by which herbal medicines produce their health benefits is their effective free radical scavenging properties. The anti-oxidant properties of the freshly prepared herbal teabags were evaluated using DPPH radical scavenging activity. The effect of storage conditions on the antioxidant properties of the 
various herbs is presented in Fig. 1. The different herbal teas containing different herbs showed differences in their DPPH radical scavenging activity, which reflects also the differences in the type and concentration of the antioxidant compounds. Fig. 1, shows a relatively high antioxidant property as compared to that of ascorbic acid. Though the effective free radical scavenging properties of ascorbic acid were higher than those of the herbal teas, they can be said to be comparable bearing in mind that the herbal teas are derived from prepared herbs. The storage condition has also been shown to have a remarkable effect on the free radical scavenging properties of the herbal teas. There were no remarkable differences between the anti-oxidant effect of the initial product and that stored in good ambient controlled conditions for 12 weeks as reflected by the DPPH radical scavenging activity of the extracts as compared to when they are stored under stress conditions.

\section{CONCLUSION}

Three variants of herbal tea containing blends of H. sabdariffa, M. oleifera, Z. officinale and C. limon were developed. The different herbal tea blends showed differences in some physicochemical properties. Such remarkable differences were in some of the intrinsic properties such as organoleptic, $\mathrm{pH}$, ash values and anti-oxidant properties as well as nonintrinsic properties such as flow, moisture content and particle size respectively. All the products showed physicochemical properties that are characteristic of a good finished herbal product. The herbal tea bags also showed discrepancies in stability that is related to the storage condition. The storage of the herbal tea bags under different environmental conditions resulted in changes in certain physicochemical parameters. Storage in a cool dark cupboard and under a stressful condition in a photo-stability chamber showed remarkable differences in the colour of the granules, $\mathrm{pH}$ of the brew and the DPPH free radical scavenging activity of the tea granules. The samples stored in the photostability chamber showed remarkable signs of deterioration when compared to those stored in a cool dark cupboard. Thus, it is recommended that the products should be stored in a cool dry place away from light.

\section{ACKNOWLEDGMENT}

This research was carried out with the support of a grant offered by the Tertiary Education Trust Fund (TETFUND) under the Kaduna State University. To Kaduna State University and TETFUND, the authors are thankful.

\section{REFERENCES}


1. McKay D. L. and Blumberg J. B. The role of tea in human health: an update. $\mathrm{J}$ Am Coll Nutr. 2002; 21(1):1-13.

2. Khan N, Mukhtar H. Tea and health: studies in humans. Curr Pharm Des. 2013; 9(34): 6141-6147

3. Builders PF. Introduction to herbal medicine. In Herbal Medicine. Builders PF. Ed. Intech 2019. DOI: 10.5772/intechopen.78661.

4. Byeon JO, Han JS. A study on perception and actual status of utilization for green tea. Korean $\mathbf{J}$ Food Culture .2004; 19(2):184-192.

5. Khan N, Mukhtar H. Multitargeted therapy of cancer by green tea polyphenols. Cancer Lett. 2008; 269: 269-280.

6. Bender DA. Benders' Dictionary of nutrition and food technology. 2003; 7th Ed, CRC.

7. Tariq M, Naveed A, Ali KB. The morphology, characteristics and medicinal properties of Camellia sinensis ' tea. J. Med. Plants Res 2010; 4(19): 2028-2033.

8. Abdel-Rahman A, Anyangwe N, Carlacci L, Casper S, Danam RP, Enongene E, Erives G, Fabricant D, Gudi R, Hilmas CJ, Hines F, Howard P, Levy D, Lin Y, Moore RJ, Pfeiler E, Thurmond TS, Turujman S, Walker NJ. The safety and regulation of natural products used as foods and food ingredients. Toxicol Sci 2011; 123(2):333-348

9. Ravikumar C. Review on herbal teas. J Pharm Sc Res 2014; 6(5): 236-238.

10. Aoshima H, Hirata S, Ayabe S. Antioxidative and anti-hydrogen peroxide activities of various herbal teas. Food Chemistry 2007; 103(2): 617-622.

11. Serafini M, Del Rio D, Yao DN, Bettuzzi S, Peluso I. In: Benzie IFF, Wachtel-Galor S, Eds. Herbal Medicine: Biomol Clinic Aspec. 2nd Ed. Boca Raton (FL): 2011. CRC Press/Taylor \& Francis.

12. Yahaya T, Okpuzor J, Ajayi $\mathrm{T}$. Antioxidant activity of Roselle (Hibiscus sabdariffa), moringa (Moringa oleifera), ginger (Zingiber officinale) and ugu' (Telfairia occidentalis) in the lungs of albino rats (Rattus norvegicus) exposed to cement dust. Annual Res Rev Biol 2014; 4 (5): 736-746.

13. Sangwan A, Kawatra A, Sehgal S. Nutritional composition of ginger powder prepared using various drying methods. J Food Sci Technol 2012; 51(9): 2260-2262.

14. Charan R. Development in ginger processing. J Agril Engg 2007; 25(3): 63-66. 
15. Juszczak L, Socha R, Rożnowski J. Fortuna T, Nalepka K. Physicochemical properties and quality parameters of herb honeys. Food Chemistry 2009; 113(2): 538-542.

16. ISO 1575:1987(ed) (2015) P-Tea.

Determination of total ash.

17. World Health Organizational (1998) Quality control methods for medicinal plant materials, WHO Geneva Switzerland. Materials, WHO Geneva Switzerland, p. 128.

18. Rhizoma Curcumae longae, WHO monographs on selected medicinal plants Vol 1: 1999; World Health Organization.

19. Builders PF, Ezeobi CR, Tarfa FD, Builders MI. Assessment of the intrinsic and stability properties of the freezedried and formulated extract of Hibiscus sabdariffa (Linn). African J Pharm Pharmacol 2010; 4(6): 304-313.

20. Well J. Pharmaceutical preformulation the physicochemical properties of drug substances. In: Aulton ME. (Ed) The science of dosage form design, $2^{\text {nd }} \mathrm{Ed}$. 2003. Churchill Livingstone, Toronto, pp. 113-138.
21. Brand-Williams W, Cuvelier ME, Berse CT. Use of a free radical method to evaluate antioxidant activity. LWT Food Sc Technol 1995; 28(1): 25-30.

22. Alamgir ANM. Therapeutic use of medicinal plants and their extracts: Pharmacognosy. In: Rainsford KD. Ed. 2017; Progress in drug research. 73: 403-406.

23. Munoz AM, Civille GV. Universal, product and attribute specific scaling and the development of common lexicon in descriptive analysis. J Sens Stud 1998; 13: 57-75.

24. Ahirwal B, Ahirwal D, Ram A. Evaluation of standards and quality control parameters of herbal drugs, souvenir. Recent trends in herbal therapy 2006; 25-29.

25. Alam F, Saqib NQ. Pharmacognostic standardization and preliminary phytochemical studies of Gaultheriatrichophylla, Pharm Biol 2015; 53(12): 1711-1718.

26. European Pharmacopoeia 5th Ed. 2005 Main Vol 5, with Supplements 5.1 and 5.2 (European Pharmacopoeia).

27. Müller J, Heindl, A. Drying of medicinal plants. In R. J. Bogers, L. E. Craker, \& D. Lange (Eds.), Medicinal and aromatic plants (237-252). 2006. The Netherlands: Springer. 
28. Ali MA, Yusof YA, China NL, Ibrahim MN, Basra MA. Drying kinetics and colour analysis of Moringa oleifera leaves. Agric Agric Sc Proc 2014; 2: 394-400.

29. Shruthi VH, Ramachandra CT, Nidoni U, Hiregoudar S, Naik N, Kurubar A. Physico-chemical, nutritional and functional properties of roselle (Hibiscus sabdariffa L.). Intern Curr Micro Appl Sc. 2017; 6(10): 546- 612.

30. Debjit BS. Duraivel, RAN. Kumar SKP (2014). Tablet manufacturing process and defects of tablets. Elixir Pharm; 70: 24368-24374.

31. Höhne C, Kruse SO, Dammertz W, Kroll, U, Tegtmeier W, Steinhoff B. On-going stability testing of herbal medicinal products. Pharm Ind 2011; 73(8): 1401-1412.

32. Ramprasath R., Geetha, K. G. and Selva R. T. Isolation of Natural Dyes from Hibiscus Rosa Sinensis and Marigold Flower and Dyeing Properties of the Dyes On Cotton Cloth. IOSR-JAC 10(5). I. 74-79.

33. Delgado-Vargas F, Jiménez AR, Paredes-López O. Natural pigments: carotenoids, anthocyanins and betalains -characteristics, biosynthesis, processing and stability. Critic Rev Food Sc Nut 2000; 40: 173-289.
34. Kumamoto M, Sonda T. Evaluation of the antioxidative activity of tea by an oxygen electrode method. Biosc, Biotech Biochem 1998; 62: 175-177.

35. Friedman M. Jürgens HS. Effect of $\mathrm{pH}$ on the stability of plant phenolic compounds. J. Agric Food Chem 2000; 48 (6): 2101-2110.

36. Choi HJ, Lee WS, Hwang SJ, Lee IJ, Shin DH, Kim HY, Kim KU. Changes in chemical compositions of green tea (Camellia sinensis L.) under the different extraction conditions. Korean J Life Sc 2000; 10: 202-209.

37. Chan E, Lim Y, Chong K, Joash T, Wong SK. Antioxidant properties of tropical and temperate herbal teas. J Food Comp Anal: 2009; 23: 185-189.

38. Rodrigues MJ, Neves V, Martins A. Custódio L. In vitro antioxidant and anti-inflammatory properties of Limonium algarvense flowers' infusions and decoctions: A comparison with green tea (Camellia sinensis). Food Chem 2016; 200(1): 322-329.

39. Lobo V, Patil A. Phatak A, Chandra N. Free radicals, antioxidants and functional foods: Impact on human health. Pharmacogn Rev 2010; 4(8): 118-126.

40. Rao AL, Bharani M, Pallavi V. Role of antioxidants and free radicals in health 
Table 1: Ratio of ingredients used in the working formula of the herbal tea blends

\begin{tabular}{ccccc}
\hline Sample & $\begin{array}{c}\text { Herbiscus } \\
\text { sabderifer }\end{array}$ & $\begin{array}{c}\text { Zingiber } \\
\text { officianalis }\end{array}$ & $\begin{array}{c}\text { Moringa } \\
\text { oleifera }\end{array}$ & Citrus limon \\
\hline 1 & 1 & 1 & 0.5 & 1 \\
2 & 1 & 1 & 1 & 1 \\
3 & 1 & 2 & 0.25 & 1 \\
\hline
\end{tabular}

Table 2: Organoleptic properties of tea granules

\begin{tabular}{ccccc}
\hline Sample & Colour & Smell & Taste & Texture \\
\hline 1 & Mottled oxblood & Chokky Aromatic & Sour and spicy & Coarse granules \\
2 & $\begin{array}{c}\text { Mottled dark green } \\
\text { and gray particle }\end{array}$ & Pungent & Spicy & Coarse granules \\
3 & $\begin{array}{c}\text { Mottled dark green } \\
\text { and gray with a } \\
\text { tint of red particles }\end{array}$ & $\begin{array}{c}\text { Characteristic } \\
\text { aromatic }\end{array}$ & Sour and spicy & Coarse granules \\
\hline
\end{tabular}

Table 3: Some physicochemical properties of the herbal teas

\begin{tabular}{rlllllll}
\hline Sample & $\begin{array}{l}\text { Ash } \\
\text { value } \\
(\boldsymbol{\%})\end{array}$ & $\begin{array}{l}\text { Extractive } \\
\text { matter }(\boldsymbol{\%})\end{array}$ & $\begin{array}{l}\text { pH of } \\
\text { brew } \\
\text { solution }\end{array}$ & $\begin{array}{l}\text { Moisture } \\
\text { content }(\boldsymbol{\%})\end{array}$ & $\begin{array}{l}\text { CI } \\
(\boldsymbol{\%})\end{array}$ & $\begin{array}{l}\text { AR } \\
(\boldsymbol{\%})\end{array}$ & $\begin{array}{l}\text { Dust } \\
\text { leak }(\boldsymbol{\%})\end{array}$ \\
\hline 1 & 3.0 & $42.0 \pm 1.20$ & $1.73 \pm 0.20$ & 9.0 & 12.57 & 19.80 & $0.18 \pm 0.03$ \\
2 & 4.0 & $29.8 \pm 1.32$ & $1.60 \pm 0.22$ & 7.3 & 23.71 & 20.55 & $0.35 \pm 0.01$ \\
3 & 4.5 & $26.5 \pm 1.12$ & $2.04 \pm 0.22$ & 7.9 & 19.68 & 21.60 & $0.35 \pm 0.01$ \\
\hline
\end{tabular}




\section{www.niprdjopat.gov.net; niprdjopat@gmail.com}

Table 4: Effect of storage on the colour of brew

\begin{tabular}{c|cc|ll|ll}
\hline Sample & $\begin{array}{c}\text { Colour of brew after } \\
\text { production }\end{array}$ & \multicolumn{2}{|c|}{$\begin{array}{c}\text { Colour of brew 12 weeks } \\
\text { stored in a cool dry place at } \\
\text { room temperature }\left(\approx 27{ }^{\circ} \mathrm{C}\right)\end{array}$} & \multicolumn{2}{c}{$\begin{array}{c}\text { Colour of brew after 12 } \\
\text { weeks stored in a photo- } \\
\text { stability chamber at } 40{ }^{\circ} \mathrm{C} .\end{array}$} \\
\hline 1 & Blood red (Turbid) & ++ & Blood red (Turbid) & ++ & Blood red (Clear) & +++ \\
2 & Blood red (Turbid) & ++ & Blood red (Turbid) & ++ & Blood red (Clear) & +++ \\
3 & Blood red (Turbid) & ++ & Blood red (Turbid) & ++ & Blood red (Clear) & ++ \\
\hline
\end{tabular}

Table 5: $\mathrm{pH}$ of tea brew stored in the refrigerator at $0{ }^{\circ} \mathrm{C}$.

\begin{tabular}{llll}
\hline Sample & 1 & 2 & 3 \\
\hline Week 1 & 1.73 & 1.60 & 3.72 \\
Week 2 & 1.74 & 1.60 & 3.78 \\
& & & \\
Week 3 & 1.72 & 1.60 & 3.78 \\
& & & \\
Week 4 & 1.71 & 1.60 & 3.65 \\
\hline
\end{tabular}




\section{Journal of Phytomedicine and Therapeutics}

\section{Builders et al}

120

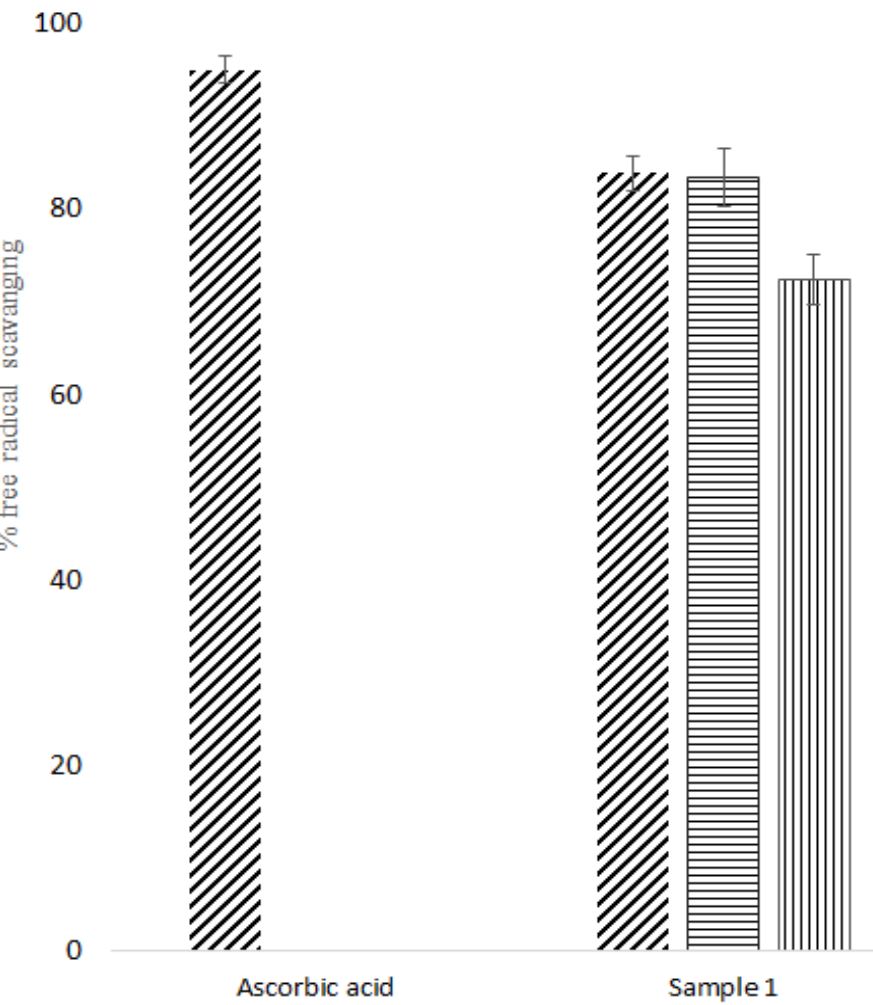

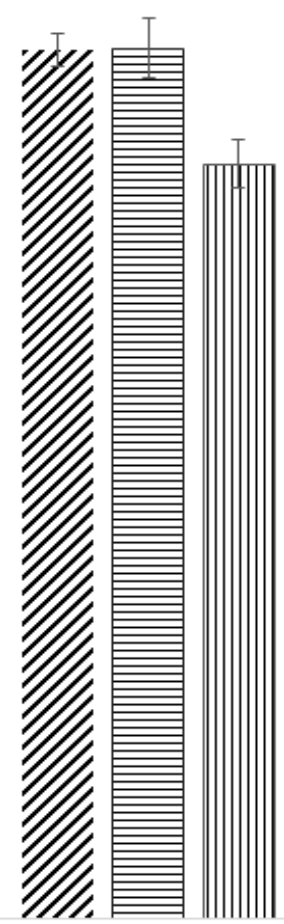

Sample 2

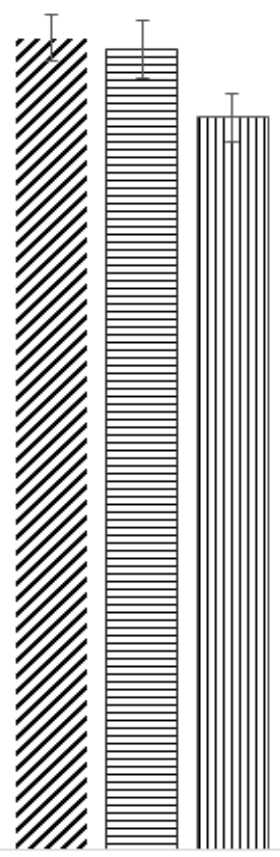

Sample 3

ขT0/After Production $\boxminus$ After 12 weeks Stored in Controled good condition $\square$ After 12 weeks stored in stress condition

Fig. 1: Effect of storage on the DPPH free radical scavenging effect of herbal teas. 